\title{
Serviço d'amores Ou a continuada reinvenção de Vicente
}

\author{
Maria Helena Serôdio
}

\footnotetext{
Serviço d'amores,
texto e enc. Maria Emilia

Correia (sobre textos de

Gil Vicente),

Teatro Nacional D. Maria II

e As Boas Raparigas,

2005 (Carla Miranda,

Maria do Céu Ribeiro

e Vitor d'Andrade),

fot. Rui Francisco.
}

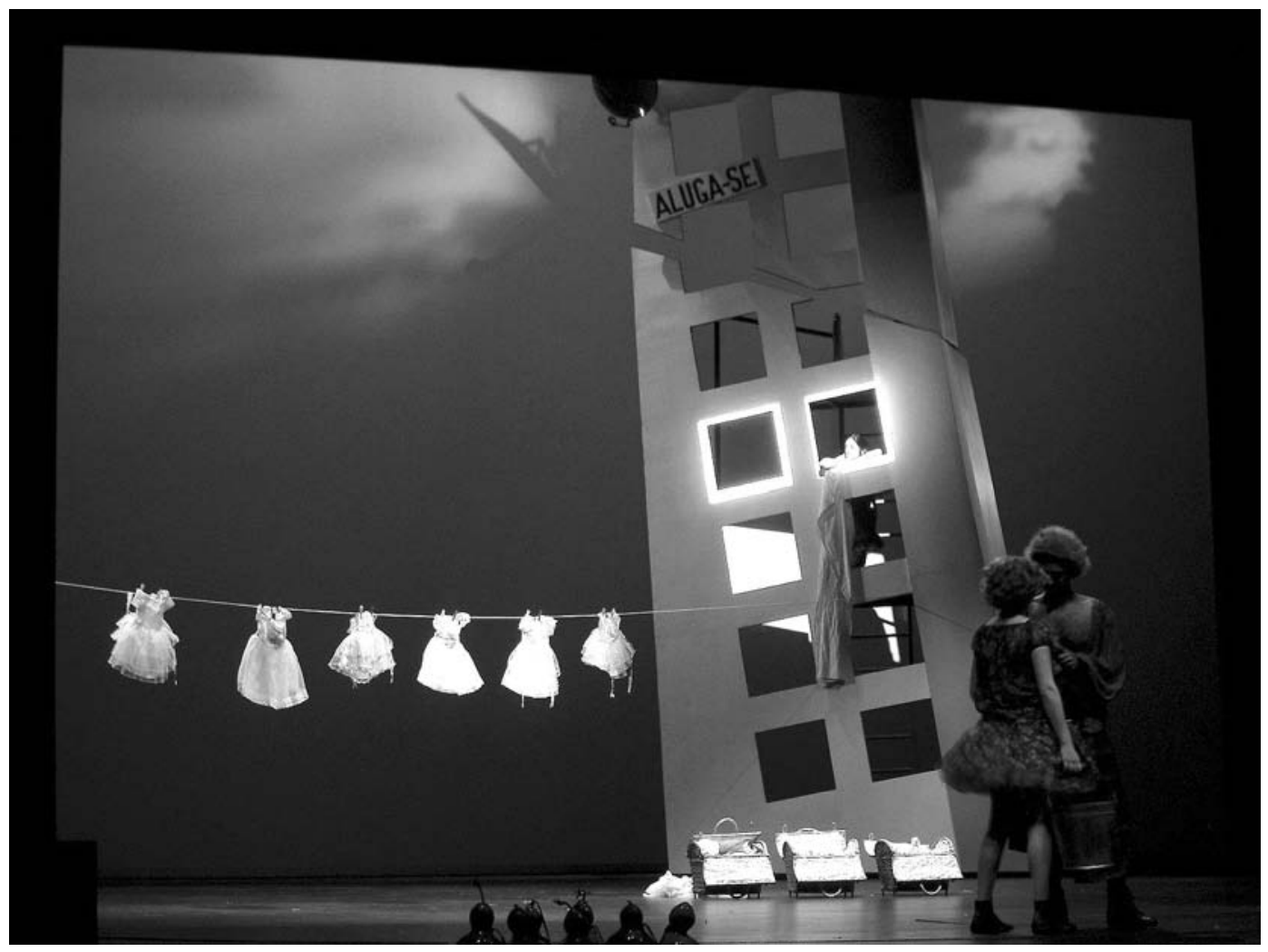

Escrevemos na "nota para a imprensa" que a atribuição de uma Menção Especial ao espectáculo Serviço d'amores com dramaturgia e encenação de Maria Emília Correia (numa produção do Teatro Nacional D. Maria II, com a colaboração d' As Boas Raparigas), se justificava pelo facto de partir de uma composição dramatúrgica "de desbragada fantasia" com que a encenadora abordava o universo vicentino, emprestando-Ihe uma atraente dimensão sensual e plástica, uma expressiva atmosfera musical, e uma intenção paródica que, não desfigurando os textos de Gil Vicente, dava uma face divertida ao desconcerto de amores que o autor neles representa.

Organizando a matéria vicentina em onze quadros e dez excertos - retirados de Festa, Feira, Físicos, Fadas, Romagem, Farelos, Velho, Lusitânia, Inês Pereira e Inverno -, o espectáculo assumia um carácter episódico, numa movimentada sucessão de cenas de amor sofrido, risível ou extravagante, mas em imaginativas fórmulas de grande plasticidade, de vibrantes universos melódicos e de belas composições figurativas em andamentos de tocante - ou provocante - inventividade.
0 espectáculo revelava, de facto, uma invulgar convergência de procedimentos artísticos que muito deveram tanto ao valor singular de cada um dos seus intervenientes, quanto a uma exemplar direcção por parte da encenadora.

Assim foi com os figurinos - estuantes de cor e expressividade - que Rafaela Mapril inventou e que acentuavam de forma notável alguns dos contrastes ou convergências que entre si as personagens revelavam. E idêntica solução inventiva trouxe a cenografia de Rui Francisco (assistido por Cláudia Armanda), com algumas soluções admiráveis (como a cama-mesa que descia da teia ou o lendário rinoceronte esculpido em rede) e que, de um modo geral, ajudavam a compor quadros que iam da nota mais festiva até à mais dorida melancolia. 0 desenho de luzes, de João Paulo Xavier, criou momentos de inesquecivel beleza (sensual, exuberante, rica de cambiantes festivos) e outros em que se lia a mais funda tristeza, como no branco gélido que acompanhava a velha na travessia da montanha nevada para ir casar. 0 som, a cargo de Rui Dâmaso, Luis Aly e António Venâncio, em 


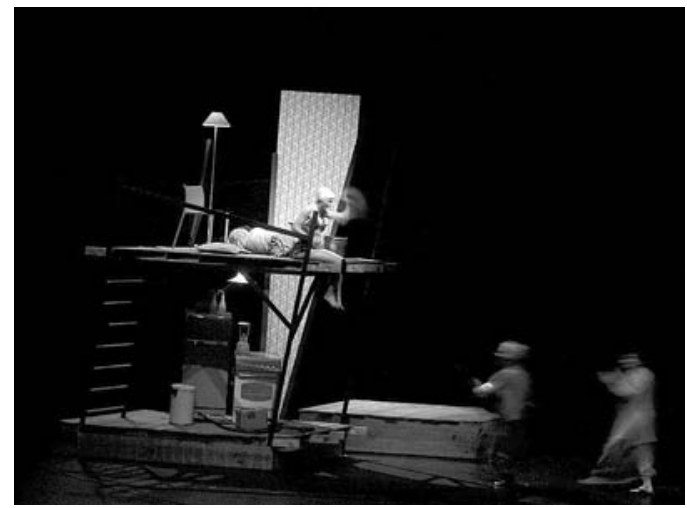

muito contribuiu para acompanhar uma musicalidade que conferiu um extraordinário ritmo ao conjunto, inventando separadores, sublinhando atmosferas, picando o ritmo, animando, enfim, um universo musical a todos os títulos excepcional.

Os actores ofereceram a tempo inteiro um conjunto notável de interpretações, revelando, para além da qualidade interpretativa de cada um, o experiente apoio vocal (na elocução e técnica vocal) de Luís Madureira, a belissima linha coreográfica de Marta Lapa e uma direcção artística - de trepidante imaginação - que Maria Emília Correia soube imprimir ao conjunto.

Assim José Neves, Rita Blanco, Sónia Neves, Maria do Céu Ribeiro, Manuel Coelho, Edmundo Rosa, Paula Mora, Avelino Lopes, Izilda Mussuela, Carla Miranda, Victor d'Andrade e João Grosso foram os lugares figurativos de inequivoca qualidade que firmaram em cena a intenção geral de um espectáculo que se propunha (e fê-lo com êxito) inventar de novo, "fugir ao desconcerto pelo divertimento, lugar do imaginário", como se escreve no programa.

Um a um, os actores iam trazendo ao palco a imensa galeria dos sofridos de amor que Vicente criou no seu teatro, num projecto que, mais do que recriar uma história, jogava com a variedade de rostos, formas, vozes e situações em que o amor é tema, e tem no seu desenvolvimento cénico as mais desvairadas modalizações. Um rodopio de cenas, afinal, em que movimento coreográfico e música criavam nexos e compunham uma paleta humana de múltiplos gestos e fazeres. Assim foi com Aires Rosado ou Torres (por José Neves), Genebra Pereira e Moça do Velho da horta (por Rita Blanco), Marta Dias ou Isabel (por Sónia Neves), Lediça ou Velha (por Maria do Céu Ribeiro), Clérigo, escudeiro ou Brisco (por Manuel Coelho), Dinis Lourenço ou Apariço (por Edmundo Rosa), Velha (por

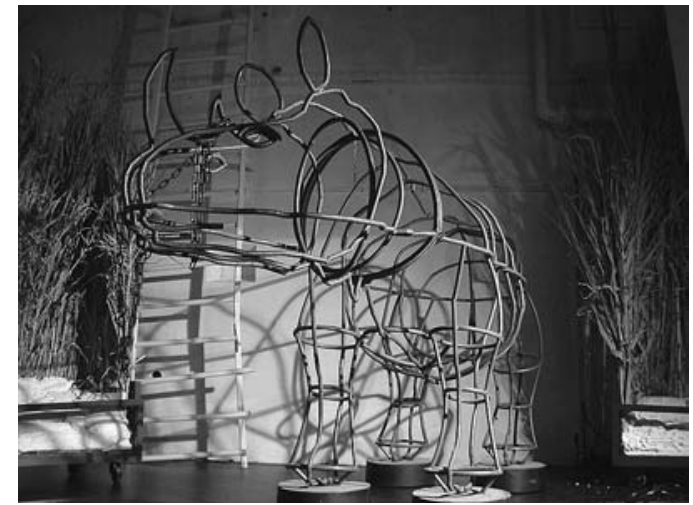

Paula Mora), Brásia Dias ou Mãe do Auto da Lusitânia (por Carla Miranda), Rascão e Cortesão (por Vitor d'Andrade) e Diabo ou Velho (por João Grosso).

Muitas foram as linguagens artisticas que convergiram em palco, como bem verificou Maria João Brilhante na sua análise ao espectáculo publicada na revista Sinais de cena - "do circo ao musical, do burlesco à farsa"(Brilhante 2004: 82). 0 jogo estendia-se ainda na acentuação de estereótipos sociais, na citação - em jeito de paródia - de outros espectáculos, bem como nas mais diversas modalidades de desenhar em cena as razões da sensualidade.

Voltaria à análise de Maria João Brilhante para acrescentar à riqueza do espectáculo uma nota relativamente a um outro elemento importante também desta extravagância vicentina:

Quanto ao humor, se por vezes ele se manifesta através da escatologia, rebaixando possiveis idealizações do amor, noutros momentos reveste-se de uma comovente e cúmplice ternura. Assim, na cena de Físicos, o riso nasce da boçalidade do Moço, dos traços grotescos dos médicos e dos libidinosos delírios do clérigo, mas nos dois quadros que mais nos tocam - talvez por neles se condensarem a grandeza e a fragilidade do humano - Velho e Velha são ridículos nos seus amores fora de época e belos na desmesura dos seus sonhos de amor. (Ibidem: 83)

Estas são, pois, algumas das razões que nos parecem justificar plenamente a Menção Especial que atribuimos ao espectáculo Serviço d'amores na pessoa da sua encenadora Maria Emília Correia.

Talvez devêssemos, porém, acrescentar que esta não foi seguramente uma invenção isolada da encenadora que, tendo-se iniciado no teatro como actriz em 1970, no
Serviço d'amores, texto e enc. Maria Emilia Correia (sobre textos de Gil Vicente), Teatro Nacional D. Maria II e As Boas Raparigas, 2005 (Paula Mora e Sónia Neves), fot. Rui Francisco.

Serviço d'amores, texto e enc. Maria Emilia Correia (sobre textos de Gil Vicente), Teatro Nacional D. Maria II e As Boas Raparigas, 2005 (Composição cenográfica fora do espectáculo), fot. Rui Francisco. 
Serviço d'amores, texto e enc. Maria Emilia Correia (sobre textos de

Gil Vicente)

Teatro Nacional D. Maria

e As Boas Raparigas, 2005 (Carla Miranda,

José Neves,

Manuel Coelho

e Vitor d'Andrade)

fot. Rui Francisco.

Serviço d'amores,

texto e enc. Maria Emilia

Correia (sobre textos de

Gil Vicente)

Teatro Nacional D. Maria I

e As Boas Raparigas,

2005 (João Grosso),

fot. Rui Francisco.

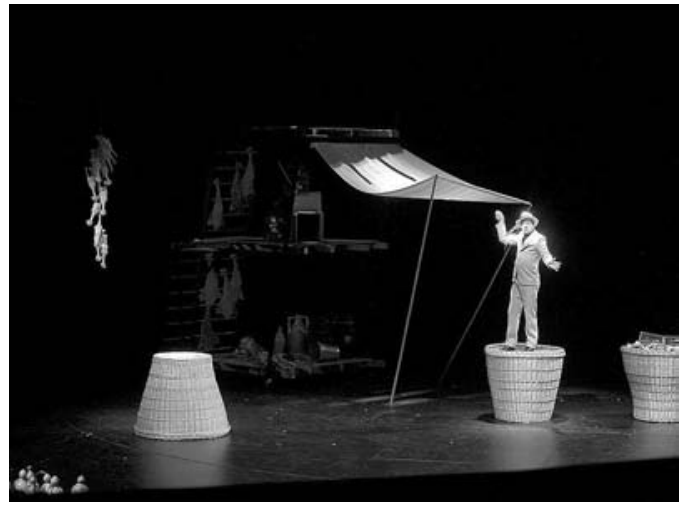

Teatro Experimental do Porto, foi construindo uma carreira artística muito variada, que vem envolvendo outras aptidões e oferecendo as mais ousadas experimentações com textos de autores portugueses. Com efeito, se no campo da sua actuação como actriz, Maria Emília Correia passou por companhias tão diversas - mas tão exigentes também como Os Cómicos, a Cornucópia, o Grupo Teatro Hoje, entre outras, é visivel a atracção que vem mais recentemente sentindo por textos que exigem uma apropriação dramatúrgica para subirem ao palco. Lembremos, por exemplo, alguns dos espectáculos que dirigiu, como 0 avião de Tróia (1996) sobre texto de Luiza Neto Jorge, O gato que chove (fantasia cénica), em 1997, sobre textos vários de Mário Cesariny de Vasconcelos, Vinha-d'alhos (1999) em torno de Lucialima, de Maria Velho da Costa, ou a bela invenção de Menino ao colo - momentos e lugares da vida do extravagante Santo António (2002), sobre peça poética de Armando Silva Carvalho.

Com uma presença cénica muito cativante recordemos as belas figurações de Maria, no Woyzeck, da Cornucópia (1977), a Menina Júlia, da peça de Strindberg, no Teatro da Graça (1979), ou, mais recentemente, como
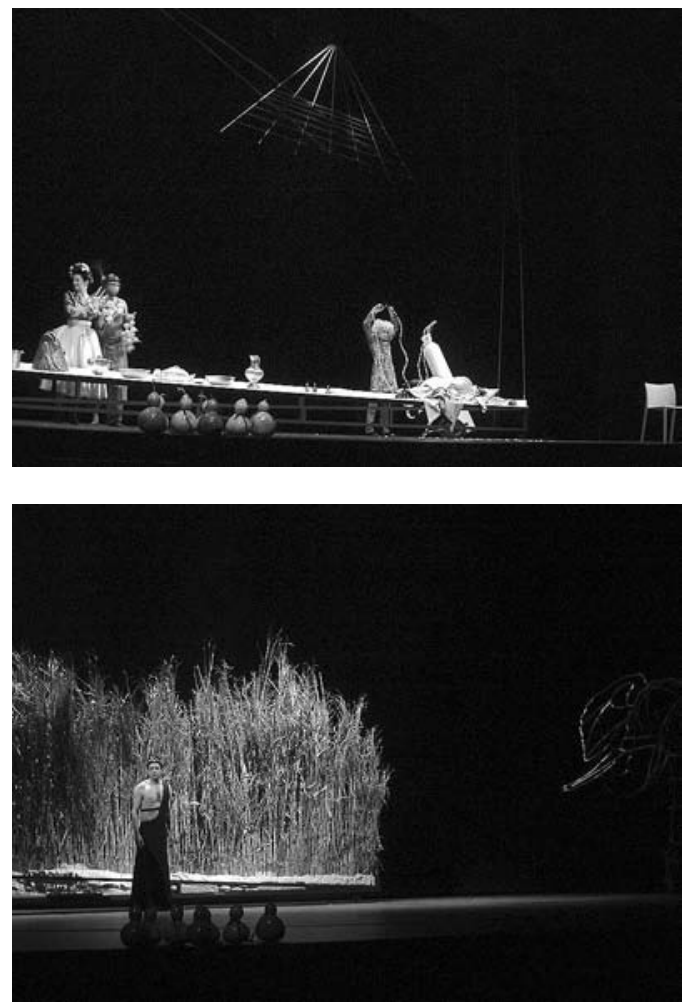

Ela em Encontro com Rita Hayworth, no Teatro Aberto (2002) -, Maria Emilia Correia alia a segurança de uma actriz experimentada a uma intervenção cultural que passou por experiências na rádio em programas culturais, até à mais recente inclinação para a criação múltipla de objectos cénicos: relendo os autores, afeiçoando dramaturgicamente textos que podem não ter sido escritos para teatro, dirigindo actores em universos de singular inventividade. Correndo, por isso mesmo, alguns riscos, desacertando por vezes, mas não desistindo desta vontade obstinada de criar mundos imaginários em diálogo com alguns dos nossos melhores escritores.

\section{Referência bibliográfica}

BRILHANTE, Maria João (2005), "Uma 'desordem harmónica' ou uma estravagância pós-moderna", in Sinais de cena n. ${ }^{\circ}$, Junho, APCT/CET, Porto, Campo das Letras, pp. 94-98. 